\title{
Prevotella falsenii sp. nov., a Prevotella intermedia- like organism isolated from monkey dental plaque
}

\author{
Correspondence \\ Mitsuo Sakamoto \\ sakamoto@jcm.riken.jp
}

\author{
Mitsuo Sakamoto, ${ }^{1} \dagger$ Hidefumi Kumada, ${ }^{2}+$ Nobushiro Hamada, ${ }^{2}$ \\ Yusuke Takahashi, ${ }^{2}$ Masaaki Okamoto, ${ }^{3}$ Mohammad Abdul Bakir ${ }^{1}$ \\ and Yoshimi Benno ${ }^{1}$
}
${ }^{1}$ Microbe Division/Japan Collection of Microorganisms, RIKEN BioResource Center, Wako, Saitama 351-0198, Japan
${ }^{2}$ Department of Oral Microbiology, Kanagawa Dental College, 82 Inaoka-cho, Yokosuka, Kanagawa 238-8580, Japan

${ }^{3}$ Tsurumi University, School of Dental Medicine, Tsurumi, Yokohama, Kanagawa 230-8501, Japan

\begin{abstract}
Eight anaerobic, pigmented, non-spore-forming, Gram-negative, rod-shaped strains isolated from monkey oral cavities were characterized phenotypically and chemotaxonomically and their phylogenetic positions were determined using $16 \mathrm{~S}$ rRNA gene sequence analysis. The $16 \mathrm{~S}$ rRNA gene sequence analysis showed that these isolates represent a single species of the genus Prevotella. These strains were most closely related to Prevotella intermedia ATCC $25611^{\top}$, with 95.0\% 16S rRNA gene sequence similarity. The next most closely related species were Prevotella pallens and Prevotella nigrescens (92.7 and 92.1\% similarity to the respective type strains). The phenotypic and biochemical characteristics of the isolates were the same as those of $P$. intermedia JCM $12248^{\top}$ and $P$. nigrescens JCM $12250^{\top}$. The isolates could be differentiated from $P$. pallens JCM $11140^{\top}$ on the basis of mannose fermentation and $\alpha$-fucosidase activity. The isolates could not be distinguished from $P$. intermedia or $P$. nigrescens using conventional biochemical tests. DNA-DNA hybridization experiments revealed the genomic distinctiveness of these eight strains with respect to $P$. pallens JCM $11140^{\top}, P$. intermedia JCM $12248^{\top}$ and $P$. nigrescens JCM $12250^{\top}$. On the basis of these data, strains $04013,04021,04043,04052^{\top}$, 0406, 04113, 04111 and 04161 represent a novel Prevotella species, for which the name Prevotella falsenii sp. nov. is proposed. The type strain is $04052^{\top}\left(=\mathrm{JCM} 15124^{\top}=\right.$ CCUG $\left.56137^{\top}\right)$.
\end{abstract}

During studies on the oral microbiota of long-tailed macaques (Macaca fascicularis), dental plaque was the source of a number of strains comprising obligately anaerobic, pigmented, non-spore-forming, non-motile, Gram-negative rods. These isolates were phenotypically most closely related to Prevotella intermedia and Prevotella nigrescens. In addition, the isolates were tentatively identified, using a PCR technique (Baumgartner et al., 1999), as belonging to the species $P$. intermedia. The present study was designed to determine the taxonomic status of the isolates. On the basis of the results presented

\footnotetext{
†These authors contributed equally to this work.
}

The GenBank/EMBL/DDBJ accession numbers for the 16S rRNA gene sequences of strains 04013, 04021, 04043, 04052 ${ }^{\top}, 0406,04113$, 04111 and 04161 are AB429501-AB429508, respectively.

The sequence of the primer pair for $P$. intermedia and alignment of the $16 \mathrm{~S}$ rRNA gene sequences of related species are presented in a supplementary figure available with the online version of this paper. here, we propose that these strains represent a novel species of the genus Prevotella.

The strains used in the present study were maintained on Eggerth Gagnon (EG) agar (Merck), supplemented with $5 \%(\mathrm{v} / \mathrm{v})$ horse blood, for 2 days at $37{ }^{\circ} \mathrm{C}$ in an atmosphere containing $100 \% \mathrm{CO}_{2}$. Strains 04013, 04021, 04043, $04052^{\mathrm{T}}, 0406,04113,04111$ and 04161 were isolated from dental plaque collected from 12 male long-tailed macaques that were 5-6 years old. Bacteroides bile aesculin agar (Shah, 1992) was used to check whether the growth of the isolates was inhibited on this medium.

Physiological reactions were determined with an API 20A anaerobe test kit, in duplicate, as recommended by the manufacturer (bioMérieux). Metabolic end products were prepared (Holdeman et al., 1977) and analysed (Sakamoto et al., 2005a) as described previously. Fatty acid methyl esters were obtained from about $40 \mathrm{mg}$ wet cells by saponification, methylation and extraction using the method of Miller (1982), with minor modifications 
(Kuykendall et al., 1988). Cellular fatty acid profiles were determined using the MIDI microbial identification system (Microbial ID). Biochemical reactions were determined with the API Rapid ID 32A anaerobe identification kit, in duplicate, as recommended by the manufacturer (bioMérieux). Chromosomal DNA was isolated by previously described methods (Marmur, 1961; Saito \& Miura, 1963), with some modifications. DNA G $+C$ contents were determined using the HPLC method of Tamaoka \& Komagata (1984). The elution solvent was a mixture of $0.02 \mathrm{M} \mathrm{NH} \mathrm{NH}_{4} \mathrm{HO}_{4}$ and acetonitrile $(20: 1, \mathrm{v} / \mathrm{v})$. The DNA-DNA hybridization experiment was carried out in microplate wells, as described by Ezaki et al. (1989). Hybridization was performed at $43{ }^{\circ} \mathrm{C}$ for $16 \mathrm{~h}$. $16 \mathrm{~S}$ rRNA gene sequences were analysed as described previously (Sakamoto et al., 2002). Related sequences were aligned using the CLUSTAL x 2.0 program (Larkin et al., 2007) and the alignment was corrected by manual inspection. Nucleotide substitution rates ( $K_{\text {nuc }}$ values) were calculated (Kimura, 1980) after gaps and unknown bases had been eliminated. The phylogenetic tree was constructed with the neighbour-joining method (Saitou \& Nei, 1987). Bootstrap resampling analysis (Felsenstein, 1985) was performed to estimate the confidence of tree topologies.

Strains 04013, 04021, 04043, 04052 $2^{\mathrm{T}}, 0406,04113,04111$ and 04161 were obligately anaerobic, pigmented (black), non-spore-forming, non-motile, Gram-negative rods or coccobacilli. Cells on EG agar were $0.5-0.8$ by $1.6 \mu \mathrm{m}$ or 0.8 by $0.9-1.0 \mu \mathrm{m}$ in size and occurred singly. Colonies were $1-2 \mathrm{~mm}$ in diameter, brown to black, circular, entire, slightly convex and smooth on EG agar plates. Colonies of strain 04021 were slightly smaller than those of the other isolates. In addition, this strain formed aggregates in GAM broth (Nissui Pharmaceutical) culture. On Bacteroides bile aesculin agar, growth of the isolates was inhibited and aesculin hydrolysis was absent. Phenotypic and biochemical characteristics are given in the species description. The phenotypic and biochemical characteristics of the eight strains were the same as those of $P$. intermedia JCM $12248^{\mathrm{T}}$ and $P$. nigrescens $\mathrm{JCM} 12250^{\mathrm{T}}$. The strains could be differentiated from Prevotella pallens JCM $11140^{\mathrm{T}}$ on the basis of mannose fermentation and $\alpha$-fucosidase activity.

The cellular fatty acid compositions of Prevotella species have been determined previously (Sakamoto et al., 2004, 2005a, b). In this study, the cellular fatty acid compositions of the eight isolates were found to be similar to those of $P$. pallens JCM $11140^{\mathrm{T}}$, P. intermedia JCM $12248^{\mathrm{T}}$ and $P$. nigrescens JCM $12250^{\mathrm{T}}$ (Table 1). The amounts of anteiso- $\mathrm{C}_{15: 0}$ and summed feature 3 were slightly higher than in $P$. intermedia JCM $12248^{\mathrm{T}}$, while the amount of iso- $\mathrm{C}_{17: 0} 3-\mathrm{OH}$ was slightly low relative to that in P. intermedia JCM $12248^{\mathrm{T}}$.

Approximately 1500 bases of the 16S rRNA gene sequence were determined for each of the new isolates. For the phylogenetic analysis, 1359 bp (positions 56-1391 in the Escherichia coli numbering system) sequences of each species were used. 16S rRNA gene sequence analysis
Table 1. Cellular fatty acid compositions of the novel strains and type strains of related species

Strains: 1, strains 04013, 04021, 04043, 04052 ${ }^{\mathrm{T}}, 0406,04113,04111$ and 04161 (means $\pm \mathrm{SD}$ ); 2, P. intermedia JCM $12248^{\mathrm{T}} ; 3$, P. nigrescens JCM $12250^{\mathrm{T}} ; 4$, P. pallens JCM $11140^{\mathrm{T}}$. Values are percentages of total fatty acids. tr, Trace amount $(<0.5 \%) ;-$, not detected.

\begin{tabular}{|c|c|c|c|c|}
\hline Fatty acid & 1 & 2 & 3 & 4 \\
\hline \multicolumn{5}{|c|}{ Saturated straight-chain } \\
\hline $\mathrm{C}_{14: 0}$ & $0.6 \pm 0.1$ & 0.6 & - & 1.1 \\
\hline $\mathrm{C}_{16: 0}$ & $6.2 \pm 0.9$ & 5.1 & 4.1 & 5.1 \\
\hline $\mathrm{C}_{18: 0}$ & $1.4 \pm 0.4$ & 1.1 & 0.5 & 0.8 \\
\hline \multicolumn{5}{|c|}{ Unsaturated straight-chain } \\
\hline $\mathrm{C}_{13: 1} \omega 1 c$ & $1.6 \pm 0.3$ & - & 1.0 & - \\
\hline $\mathrm{C}_{14: 1} \omega 5 c$ & $\operatorname{tr}$ & $\operatorname{tr}$ & - & 0.6 \\
\hline $\mathrm{C}_{16: 1} \omega 5 c$ & - & $\operatorname{tr}$ & - & - \\
\hline $\mathrm{C}_{16: 1} \omega 7 c$ & $1.9 \pm 0.2$ & 2.1 & 2.0 & 2.6 \\
\hline $\mathrm{C}_{17: 1} \omega 8 c$ & - & 0.5 & 0.5 & - \\
\hline $\mathrm{C}_{18: 2} \omega 6,9 c$ & $5.2 \pm 0.7$ & 5.3 & 3.3 & 1.4 \\
\hline $\mathrm{C}_{18: 1} \omega 9 c$ & $18.0 \pm 2.7$ & 16.3 & 12.7 & 19.8 \\
\hline \multicolumn{5}{|l|}{ Hydroxy } \\
\hline iso- $\mathrm{C}_{16: 0} 3-\mathrm{OH}$ & $1.1 \pm 0.3$ & 1.0 & 1.0 & - \\
\hline $\mathrm{C}_{16: 0} 3-\mathrm{OH}$ & $1.2 \pm 0.5$ & 2.5 & $\operatorname{tr}$ & 2.2 \\
\hline iso- $\mathrm{C}_{17: 0} 3-\mathrm{OH}$ & $6.3 \pm 2.7$ & 16.1 & 3.3 & 15.7 \\
\hline anteiso- $\mathrm{C}_{17: 0} 3-\mathrm{OH}$ & $1.1 \pm 0.1$ & 1.3 & - & 1.7 \\
\hline \multicolumn{5}{|c|}{ Saturated branched-chain } \\
\hline iso- $\mathrm{C}_{10: 0}$ & $\operatorname{tr}$ & $\operatorname{tr}$ & - & $\operatorname{tr}$ \\
\hline iso- $\mathrm{C}_{13: 0}$ & $0.6 \pm 0.1$ & 0.7 & 0.8 & 1.1 \\
\hline iso- $\mathrm{C}_{14: 0}$ & $5.5 \pm 1.6$ & 5.5 & 9.0 & 4.3 \\
\hline iso- $\mathrm{C}_{15: 0}$ & $7.7 \pm 1.8$ & 10.8 & 12.5 & 12.1 \\
\hline anteiso- $\mathrm{C}_{15: 0}$ & $21.6 \pm 2.4$ & 14.0 & 22.4 & 24.5 \\
\hline iso- $\mathrm{C}_{16: 0}$ & $3.0 \pm 1.1$ & 6.2 & 5.3 & 1.5 \\
\hline iso- $\mathrm{C}_{17: 0}$ & $2.2 \pm 0.5$ & 3.8 & 3.2 & 1.4 \\
\hline anteiso- $\mathrm{C}_{17: 0}$ & $2.8 \pm 0.5$ & 2.5 & 2.2 & 1.5 \\
\hline iso- $\mathrm{C}_{18: 0}$ & - & $\operatorname{tr}$ & - & - \\
\hline iso- $\mathrm{C}_{19: 0}$ & - & 0.5 & - & - \\
\hline \multicolumn{5}{|l|}{ Summed features ${ }^{\star}$} \\
\hline 3 & $12.5 \pm 4.7$ & 1.2 & 14.3 & - \\
\hline 10 & $2.1 \pm 0.3$ & 1.7 & 1.3 & 2.2 \\
\hline
\end{tabular}

${ }^{\star}$ Summed features are groups of two or three fatty acids that cannot be separated by the MIDI system. Summed feature 3 contained an unknown fatty acid with an equivalent chain-length of 13.570 and/or iso- $\mathrm{C}_{15: 0}$ ALDE. Summed feature 10 contained one or more of an unknown fatty acid with an equivalent chain-length of 17.834 and/or $\mathrm{C}_{18: 1} \omega 11 c / \omega 9 t / \omega 6 t$.

showed that the isolates represented a single species of the genus Prevotella (Fig. 1). The levels of sequence similarity among the eight strains were above $99.0 \%$. These eight strains were most closely related to $P$. intermedia ATCC $25611^{\mathrm{T}}$, with $95.0 \%$ 16S rRNA gene sequence similarity; the next most closely related species were $P$. pallens and $P$. nigrescens ( 92.7 and $92.1 \%$ similarity to the respective type strains). In a preliminary examination using the species-specific primer for $P$. intermedia (Baumgartner et al., 1999), these isolates were identified as 


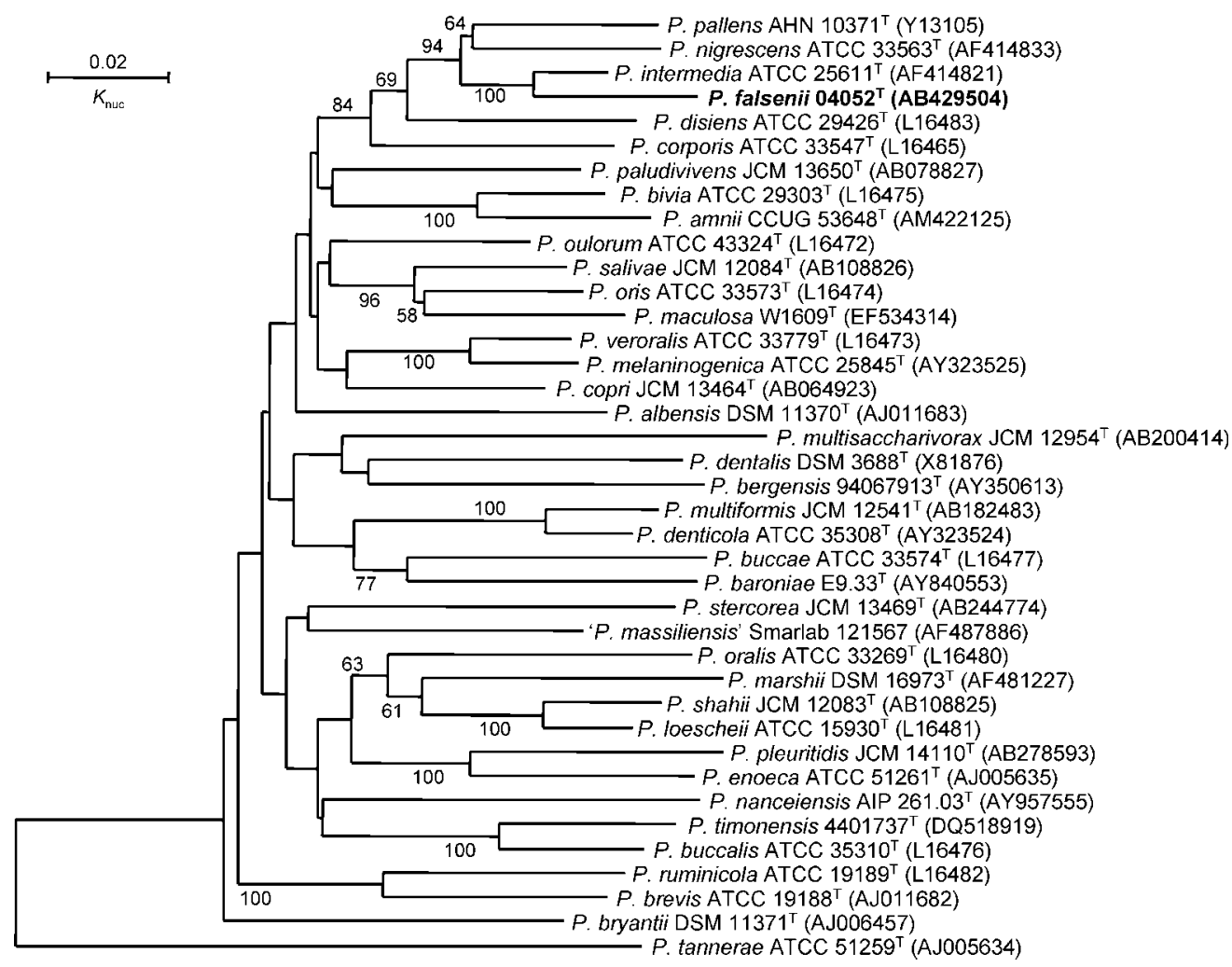

Fig. 1. Neighbour-joining phylogenetic tree, based on 16S rRNA gene sequences, showing the position of the novel strains within the genus Prevotella. Accession numbers are shown in parentheses. Numbers at nodes indicate bootstrap percentages (based on 1000 replicates); values below $50 \%$ are not shown. Bar, 0.02 substitutions per nucleotide position.

belonging to the species $P$. intermedia. The sequence alignment indicated that the sequences of the primer pair for $P$. intermedia and those of target regions of the isolates were almost the same (Supplementary Fig. S1, available in IJSEM Online). Consequently, non-specific amplification resulted in misidentification. Accurate discrimination between $P$. intermedia and these isolates will require further development of species-specific primers.

The DNA G + C contents of strains 04013, 04021, 04043, $04052^{\mathrm{T}}, 0406,04113,04111$ and 04161 were 44.9, 47.7, $46.0,45.2,44.7,45.9,44.7$ and $44.6 \mathrm{~mol} \%$, respectively. These values are slightly higher than those of $P$. pallens JCM $11140^{\mathrm{T}}$ (40.4 mol\%), $P$. intermedia JCM $12248^{\mathrm{T}}$ (43.1 $\mathrm{mol} \%)$ and $P$. nigrescens $(40-44 \mathrm{~mol} \%$; Shah \& Gharbia, 1992). The levels of DNA relatedness between the isolates and $P$. pallens JCM $11140^{\mathrm{T}}$, $P$. intermedia JCM $12248^{\mathrm{T}}$ and $P$. nigrescens JCM $12250^{\mathrm{T}}$ were 3.6-18.2, 2.0 3.8 and $11.8-31.0 \%$, respectively. The levels of DNA relatedness observed demonstrate the genomic distinctiveness of these eight strains with respect to the type strains of $P$. pallens, $P$. intermedia and $P$. nigrescens.

On the basis of the above-mentioned findings, strains 04013, 04021, 04043, 04052 ${ }^{\mathrm{T}}, 0406,04113,04111$ and 04161 represent a novel species of the genus Prevotella, for which the name Prevotella falsenii sp. nov. is proposed. Conventional biochemical tests are unable to differentiate $P$. falsenii from $P$. intermedia and $P$. nigrescens. $16 \mathrm{~S}$ rRNA gene sequence analysis is recommended for unequivocal identification of these three species.

\section{Description of Prevotella falsenii sp. nov.}

Prevotella falsenii (fal.se' ni.i. N.L. gen. masc. n. falsenii of Falsen, to honour the contemporary Norwegian microbiologist Enevold Falsen, for his lifelong interest in bacterial taxonomy and for his systematic characterization of bacteria at the Culture Collection of the University of Göteborg).

Cells are obligately anaerobic, pigmented, non-sporeforming, non-motile, Gram-negative rods or coccobacilli $(0.5-0.8 \times 1.6 \mu \mathrm{m}$ or $0.8 \times 0.9-1.0 \mu \mathrm{m})$. Colonies are $1-$ $2 \mathrm{~mm}$ in diameter, brown to black, circular, entire, slightly convex and smooth on EG agar plates. Growth is inhibited in the presence of $20 \%(\mathrm{w} / \mathrm{v})$ bile. Acid is produced from glucose, maltose, D-mannose, raffinose and sucrose, but not from L-arabinose, cellobiose, glycerol, lactose, Dmannitol, melezitose, L-rhamnose, salicin, D-sorbitol, trehalose or D-xylose. Aesculin is not hydrolysed. Indole is produced. Gelatin is digested. Catalase and urease are not 
produced. With API Rapid ID 32A, positive reactions are obtained for $\alpha$-glucosidase, $\alpha$-fucosidase, indole production, alkaline phosphatase, arginine arylamidase, leucyl glycine arylamidase, alanine arylamidase and glutamyl glutamic acid arylamidase. Mannose and raffinose are fermented. All of the other tests performed (for urease, arginine dihydrolase, $\alpha$-galactosidase, $\beta$-galactosidase, 6 phospho- $\beta$-galactosidase, $\beta$-glucosidase, $\alpha$-arabinosidase, $\beta$-glucuronidase, $N$-acetyl- $\beta$-glucosaminidase, glutamic acid decarboxylase, nitrate reduction, proline arylamidase, phenylalanine arylamidase, leucine arylamidase, pyroglutamic acid arylamidase, tyrosine arylamidase, glycine arylamidase, histidine arylamidase and serine arylamidase) give negative results. The major end products (from $1 \%$ peptone $/ 1 \%$ yeast extract $/ 1 \%$ glucose broth cultures) are succinic and acetic acids. Both non-hydroxylated and 3hydroxylated long-chain fatty acids are present. The major cellular fatty acids are anteiso- $\mathrm{C}_{15: 0}$ and $\mathrm{C}_{18: 1} \omega 9 c$. The DNA $\mathrm{G}+\mathrm{C}$ content of the type strain is $45.2 \mathrm{~mol} \%$.

The type strain, $04052^{\mathrm{T}}\left(=\mathrm{JCM} 15124^{\mathrm{T}}=\right.$ CCUG $\left.56137^{\mathrm{T}}\right)$, was isolated from monkey dental plaque. Seven additional strains [04013 (=JCM 15121), 04021 (=JCM 15122), 04043 (=JCM 15123), 0406 (=JCM 15125), 04113 (=JCM 15126), 04111 (=JCM 15127) and 04161 (=JCM 15128)], from the same source, are included in this species.

\section{References}

Baumgartner, J. C., Bae, K. S., Xia, T., Whitt, J. \& David, L. L. (1999). Sodium dodecyl sulfate-polyacrylamide gel electrophoresis and polymerase chain reaction for differentiation of Prevotella intermedia and Prevotella nigrescens. J Endod 25, 324-328.

Ezaki, T., Hashimoto, Y. \& Yabuuchi, E. (1989). Fluorometric deoxyribonucleic acid-deoxyribonucleic acid hybridization in microdilution wells as an alternative to membrane filter hybridization in which radioisotopes are used to determine genetic relatedness among bacterial strains. Int J Syst Bacteriol 39, 224-229.

Felsenstein, J. (1985). Confidence limits on phylogenies: an approach using the bootstrap. Evolution 39, 783-791.

Holdeman, L. V., Cato, E. P. \& Moore, W. E. C. (1977). Anaerobe Laboratory Manual, 4th edn. Blacksburg, VA: Virginia Polytechnic Institute and State University.
Kimura, M. (1980). A simple method for estimating evolutionary rates of base substitutions through comparative studies of nucleotide sequences. J Mol Evol 16, 111-120.

Kuykendall, L. D., Roy, M. A., O’Neill, J. J. \& Devine, T. E. (1988). Fatty acids, antibiotic resistance, and deoxyribonucleic acid homology groups of Bradyrhizobium japonicum. Int J Syst Bacteriol 38, 358-361.

Larkin, M. A., Blackshields, G., Brown, N. P., Chenna, R., McGettigan, P. A., McWilliam, H., Valentin, F., Wallace, I. M., Wilm, A. \& other authors (2007). CLUSTAL $W$ and CLUSTAL $X$ version 2.0. Bioinformatics 23, 2947-2948.

Marmur, J. (1961). A procedure for the isolation of deoxyribonucleic acid from microorganisms. J Mol Biol 3, 208-218.

Miller, L. T. (1982). Single derivatization method for routine analysis of bacterial whole-cell fatty acid methyl esters, including hydroxy acids. J Clin Microbiol 16, 584-586.

Saito, H. \& Miura, K. (1963). Preparation of transforming deoxyribonucleic acid by phenol treatment. Biochim Biophys Acta 72, 619-629.

Saitou, N. \& Nei, M. (1987). The neighbor-joining method: a new method for reconstructing phylogenetic trees. Mol Biol Evol 4, 406425.

Sakamoto, M., Suzuki, M., Umeda, M., Ishikawa, I. \& Benno, Y. (2002). Reclassification of Bacteroides forsythus (Tanner et al. 1986) as Tannerella forsythensis corrig., gen. nov., comb. nov. Int J Syst Evol Microbiol 52, 841-849.

Sakamoto, M., Suzuki, M., Huang, Y., Umeda, M., Ishikawa, I. \& Benno, Y. (2004). Prevotella shahii sp. nov. and Prevotella salivae sp. nov., isolated from the human oral cavity. Int J Syst Evol Microbiol 54, 877-883.

Sakamoto, M., Huang, Y., Umeda, M., Ishikawa, I. \& Benno, Y. (2005a). Prevotella multiformis sp. nov., isolated from human subgingival plaque. Int J Syst Evol Microbiol 55, 815-819.

Sakamoto, M., Umeda, M., Ishikawa, I. \& Benno, Y. (2005b). Prevotella multisaccharivorax sp. nov., isolated from human subgingival plaque. Int J Syst Evol Microbiol 55, 1839-1843.

Shah, H. N. (1992). The genus Bacteroides and related taxa. In The Prokaryotes, 2nd edn, pp. 3593-3607. Edited by A. Balows, H. G. Trüper, M. Dworkin, W. Harder \& K. H. Schleifer. New York: Springer.

Shah, H. N. \& Gharbia, S. E. (1992). Biochemical and chemical studies on strains designated Prevotella intermedia and proposal of a new pigmented species, Prevotella nigrescens sp. nov. Int J Syst Bacteriol 42, 542-546.

Tamaoka, J. \& Komagata, K. (1984). Determination of DNA base composition by reversed-phase high-performance liquid chromatography. FEMS Microbiol Lett 25, 125-128. 